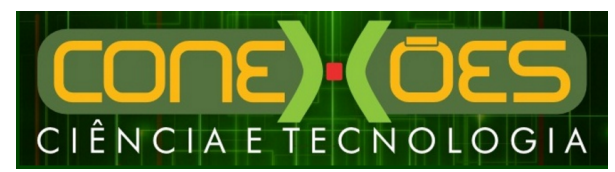

A CONTRIBUIÇÃO DA REESCRITA PARA A APRENDIZAGEM DE INGLÊS-LE

\title{
A CONTRIBUIÇÃO DA REESCRITA PARA A APRENDIZAGEM DE INGLÊS-LE
}

\author{
CRistiane Rodrigues VieirA ${ }^{1}$, RAIMUndo LUiZ do NASCIMENTO ${ }^{1}$ \\ ${ }^{1}$ Universidade Regional do Cariri - URCA \\ <profacristianevieira@hotmail.com>|rraluna2003@yahoo.com.br>
}

DOI: 10.21439/conexoes.v12i2.1439

\begin{abstract}
Resumo. A partir de um estudo de caso feito com um informante, aluno do curso de Letras, português/inglês, da Universidade Regional do Cariri, discutiremos, neste artigo, como a reescrita é necessária para a diminuição dos erros na interlíngua escrita e consequente progresso de aprendizes durante o processo de aprendizagem de inglês-LE. Para atingir este propósito, apresentaremos os modelos de escrita propostos por Hayes; Flowers (1981), Seow (2002), a Teoria da Interlíngua, proposta por Selinker (1974), as pesquisas feitas por Menegassi (2001) e Fiad; Barros (2003) sobre reescrita de textos. A análise mostrou que mais da metade das formas incorretas foram corrigidas pelo próprio informante na fase da reescrita e, dos erros que permaneceram nesta fase, o informante só não conseguiu apontar a forma correta de dois deles, quando respondeu ao questionário de sondagem. Além do mais, o informante afirmou que alguns erros foram cometidos pela pressão de ter que escrever algo em pouco tempo. Esse estudo de caso indica que a maioria dos erros ocorre na fase do rascunho, que normalmente é a única chance que os alunos têm para escrever um texto e apresentá-lo ao/a professor/a para ser avaliado. Isso implica dizer que se ao aprendiz fossem dadas as oportunidades de reler e reescrever seus textos a maioria das formas erradas seria por ele mesmo corrigida, tornando-o mais conhecedor dos fatores operantes no desenvolvimento da sua interlíngua.
\end{abstract}

Palavras-chaves: Texto. Reescrita. Interlíngua Escrita.

Abstract. From a case study carried out with an informant, undergraduate student of the Language and Literature Course at the Regional University of Cariri, we will discuss how the rewriting is necessary to reduce mistakes in written interlanguage and the consequent progress of English as a Second Language. To achieve such an objective, we will present the writing models proposed by Hayes; Flowers (1981) and Seow (2002), The Interlanguage Theory, proposed by Selinker (1974) and the research done by Menegassi (2001) and Fiad; Barros (2003) on text rewriting. The analysis showed that more than half of the errors were corrected by the informant in the rewrite phase, and the remaining ones from this phase, the informant only failed to point the correct form of two of them when he answered the survey questionnaire. In addition, the informant said that some mistakes were made by the pressure of having to write something in a short time. This case study indicates that most errors occur in the draft phase, which is usually the only chance students have to write a text and present it to the teacher to be evaluated. This implies that if the students were given the opportunity to reread and rewrite their texts most of the errors would be corrected by themselves, making them more knowledgeable of the factors operating in the development of their interlanguage.

Keywords: Text. Rewriting. Written Interlanguage. 


\section{INTRODUÇÃO}

A aprendizagem de línguas estrangeiras ainda é uma caixa preta na grande área de Aquisição de Línguas, principalmente no que diz respeito às incertezas de sucesso dos aprendizes. Não basta apenas se matricular em um curso de línguas, comprar o material didático e frequentar assiduamente as aulas para que a aprendizagem ocorra, haja vista o percentual pequeno apontado por Selinker (1974) de que apenas 5\% dos aprendizes conseguem alcançar a proficiência de um nativo, bem como o esvaziamento das turmas de nível mais avançado nos cursos de idiomas. A Análise de Erros, também, não provou ser tão eficaz como se pensava, quando da sua criação (CORDER, 1974), no que diz respeito à correção do professor e consequente eliminação do erro pelo aluno, pois algumas formas erradas são recorrentes na interlíngua do aprendiz.

Contudo, em se tratando da interlíngua escrita, existe a possibilidade dos erros diminuírem se o aprendiz reescrever seu texto, o que sugere uma reflexão pedagógica acerca do tempo e das condições dadas aos aprendizes para produção do texto (WANG, 2012). Muitos alunos se sentem frustrados quando recebem de volta suas produções textuais com as devidas correções feitas pelo professor pelo fato deles reconhecerem a forma correta de algumas construções (vocábulos, sentenças etc), mas por diversos motivos como, por exemplo, cansaço, pressa, estresse, pressão ao serem avaliados etc, acabam cometendo erros que já deveriam ter sido superados.

Este trabalho tem como objetivo discutir como a reescrita de textos é necessária para a diminuição dos erros na interlíngua escrita e para o consequente progresso de aprendizes durante o processo de aprendizagem inglês-língua estrangeira (LE).

\section{O TEXTO E O PROCESSO DE REESCRITA}

A produção de texto escrito não é tarefa simples de ser concretizada. Há, na atualidade, uma preocupação de estudiosos da linguagem em dotar os aprendizes (estudantes e profissionais que lidam com a comunicação) dos meios necessários para a sua produção uma vez que esse processo exige uma série de decisões e escolhas, conforme expressam D'Andrea e Ribeiro (2010). A partir do estabelecimento dos propósitos sobre o que será dito, as escolhas na elaboração do texto são inevitáveis (repertório, estruturas sintáticas etc.).

Seow (2002), descrevendo sobre o ensino da produção textual, diz que a atividade de escrita compreende quatro etapas principais: planejamento, rascunho, edi- ção e revisão. Segundo ele, estes estágios nem sempre acontecem de modo linear e propõe que o estudante seja orientado para realizar a tarefa a contento, ou seja, que ao aluno seja ensinado como resolver problemas relacionados com o processo de escrita. Este autor sugere metodologias apropriadas para cada etapa a fim de obter êxito na construção do texto, a partir da sala de aula, finalizando com a revisão, a qual implica análise, uma retomada do que foi produzido. Fiad e Barros (2003. p. 10) concebem a revisão como reescrita definida como "uma atividade metaenunciativa que se constitui um retorno sobre o dizer".

Discutindo modelos de estágios da escrita, Flower e Hayes (1981) descrevem a reescrita como uma reformulação definitiva desse produto. Nesta perspectiva, $\mathrm{Me}-$ negolo e Menegolo (2011, p. 77) defendem que o autor/escritor tem a oportunidade "de olhar para seu texto com uma visão mais crítica e mais apta às mudanças". Estas tanto podem relacionar-se ao conteúdo do próprio texto, a fim de torná-lo mais legível, quanto a questões de ordem estrutural.

O estudo realizado por Menegassi (2001), sobre redações produzidas por estudantes do primeiro ano do Curso de Letras, destaca quatro operações no processo de reescrita: adição, substituição, supressão e deslocamento. Segundo o pesquisador, as intervenções, englobando as quatro operações, podem ser pontuação, ortografia, estrutura de frase etc. Essas operações (e intervenções), também, ocorrem na produção de textos em LE e são, na análise da interlíngua escrita, estudadas sob a perspectiva dos erros interlinguais, intralinguais e ambíguos, como veremos na Seção 4 deste trabalho.

Corroboramos o entendimento de Seow (2002. p. 317) quando ele nos alerta que, "a reescrita não é apenas para identificação de erros de linguagem. Ela é feita para melhorar o conteúdo global e a organização das ideias de modo que a intenção do escritor seja mais clara para o leitor.' ${ }^{1}$

Ao propormos analisar a interlíngua (IL) escrita produzida por um informante, após ter sido dada a ele a oportunidade de identificar e corrigir os erros cometidos no estágio da reescrita, e de discorrer sobre os fatores que o levaram a cometê-los, acreditamos no aumento de sua consciência a respeito dos processos envolvidos na sua aprendizagem. Em outras palavras, no momento em que o aluno identifica e corrige sentenças mal formadas, ele melhora a organização das ideias expressas

\footnotetext{
${ }^{1}$ Revising is not merely checking for language errors. It is done to improve global content and the organization of ideas so that the writers intent is made clearer to the reader (SEOW 2002. p. 317). [Tradução nossa]
} 


\section{A CONTRIBUIÇÃO DA REESCRITA PARA A APRENDIZAGEM DE INGLÊS-LE}

no texto, bem como o seu conteúdo global.

\subsection{Estudos de Interlíngua e escrita em LE}

De acordo com Selinker (1974), há no cérebro uma estrutura psicológica latente (EPL) que é ativada quando um adulto tenta produzir uma estrutura com significado na SL que ele está aprendendo. Quando as informações linguísticas alcançam o aprendiz, a EPL as transforma em identificações interlinguísticas as quais possibilitam, ao aprendiz, a violação dos sistemas da LM e da SL sob aprendizagem. Essa violação permite que a IL inicie.

Na literatura sobre ASL, o termo mais próximo da EPL é Estrutura Latente da Língua (ELL), um constructo criado por Lenneberg (1967) apud (SELINKER. 1974) para explicar a aquisição de LM, o qual é (a) um arranjo pré-determinado no cérebro, (b) o equivalente biológico da Gramática Universal e (c) transformado pela criança em estruturas concretas de uma determinada gramática de acordo com certos estágios de amadurecimento. Porém, de forma distinta da ELL de Lenneberg e do Dispositivo de Aquisição da Linguagem de Chomsky, a EPL de Selinker:

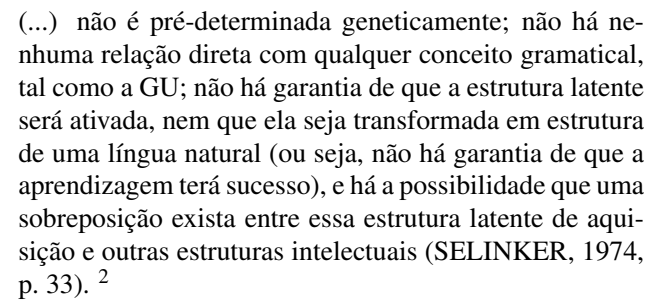

A falta de garantia de sucesso na aprendizagem de SL faz com que a possibilidade de fossilização seja bastante elevada entre os aprendizes. A fossilização consiste em não revisar a IL em relação à SL. Em outras palavras, o aprendiz não consegue mais adquirir novos elementos linguísticos da SL e comete muitos erros, o que o faz parar em algum ponto do continuum da aprendizagem.

Selinker (1974) defende que durante o desenvolvimento da IL há cinco processos psicolinguísticos de grande importância, proporcionados pela EPL, que

\footnotetext{
${ }^{2}$ There is no genetic timetable; there is no direct counterpart to any grammatical concept such as "universal grammar"; there is no guarantee that the latent structure will be activated at all; there is no guarantee that the latent structure will be "realized" into actual structure of any natural language (i.e. there is no guarantee that attempted learning will prove successful), and there is every possibility that an overlapping exists between this latent language acquisition structure and other intellectual structures(SELINKER 1974 p. 33). [Tradução nossa.]
}

atuam tanto no início desenvolvimento da IL em direção a SL, como na fossilização de itens, regras e subsistemas. Esses processos agem com um grau de maior ou menor de força no desenvolvimento do aprendiz. Vieira (2009, p. 42-43), acompanhando Selinker (1974) explica estes processos:

a) Transferência Interlinguística - A fossilização ocorre quando o aprendiz transfere regras de sua LM para a SL;

b) Transferência de Instrução - A fossilização é devido a certas falhas encontradas durante a instrução;

c) Estratégias de Aprendizagem - A fossilização acontece em decorrência do tipo de abordagem utilizada pelo aprendiz para entender o material da SL que ele está aprendendo;

d) Estratégias de Comunicação - A fossilização se dá quando o aprendiz faz uso de algumas estratégias para se comunicar com nativos;

e) Hipergeneralização - A fossilização acontece quando o aprendiz generaliza regras e características semânticas da SL e as aplica em todos os contextos indistintamente.

Luna (2010, p. 63) corroborando Selinker (1974) no que tange a natureza da fossilização nos diz que

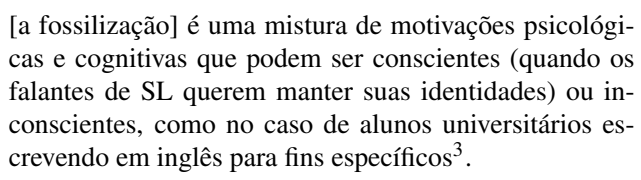

No caso desta pesquisa, os erros remanescentes e não corrigidos pelo aluno durante a resposta dada ao questionário de sondagem não podem ser considerados como indícios de fossilização, pois os elementos fossilizados precisariam ser analisados em um período maior de tempo.

Escrever na fase de desenvolvimento da interlíngua é uma tarefa que exige muito esforço, principalmente pelo fato de o aluno ter que lidar com uma gramática ainda deficiente. Em outras palavras, o aluno tem que expressar suas ideias a partir de um sistema reduzido de regras e itens lexicais da LE que ele conhece. Esse sistema de regras e itens lexicais vai, gradualmente, se

\footnotetext{
${ }^{3}$ The nature of this phenomenon is a mixture of cognitive and psychological motivations that can be conscious (when L2 speakers want to keep their identity) or unconscious, as in the case of university students writing in English for academic purposes (LUNA 2010 p. 63). [Tradução Nossa.]
} 


\section{A CONTRIBUIÇÃO DA REESCRITA PARA A APRENDIZAGEM DE INGLÊS-LE}

complexificando somente a partir do desenvolvimento do continuum da interlíngua.

Muitos são os trabalhos que têm discorrido sobre as diferenças e semelhanças entre a escrita em LM e SL, bem como sobre a influência da LM na escrita em SL (WOLFERSBERGER, 2003; LUNA, 2010, ??). A maioria deles indica que o processo da escrita em LM e em SL trilham caminhos parecidos e que as diferenças entre a escrita em LM e SL não são tão visíveis no processo de escrita, mas na competência linguística do aprendiz, ou seja, no produto. Vista assim como produto, a escrita em SL contém mais erros do que a escrita em LM para escritores com alto nível de proficiência em suas LMs.

Mesmo sabendo que a habilidade discursiva do escritor pode ser diminuída pela falta de domínio de regras sintáticas e de vocabulário, bem como pela preocupação em atingir a precisão linguística, nosso olhar, nesta pesquisa, está voltado para a escrita como produto e o que pode ser melhorado nela a partir da reescrita. Ao analisar a IL como produto, resultado do processo de escrita e reescrita, buscamos demonstrar como essa prática é necessária para a conscientização dos processos operantes durante a aprendizagem de inglês-LE.

\section{METODOLOGIA}

Com a finalidade de analisar as duas versões do texto escrito e apontar as mudanças feitas nele durante sua reescrita, conduzimos uma pesquisa exploratóriodescritiva com caráter qualitativo (explicação dos erros) e quantitativo (contagem dos erros).

O corpus da pesquisa é constituído de um texto, escrito por um informante, aluno do I semestre do curso de Letras, habilitação português e inglês, da Universidade Regional do Cariri, em duas versões ${ }^{4}$ e um questionário de sondagem respondido por ele 5 Para a coleta do corpus, foi solicitado ao informante que escrevesse

\footnotetext{
${ }^{4} \mathrm{~A}$ intenção desta atividade de produção textual era pilotar uma pesquisa na tentativa de saber se valeria a pena concorrer a uma bolsa no Programa Institucional de Bolsas de Iniciação Científica da URCA (PIBIC/URCA). Para a primeira versão do texto estavam presentes na sala todos os alunos da turma (oito ao todo) e para a segunda versão estavam presentes apenas 6 alunos. No entanto, uma greve de professores, alunos e funcionários técnico-administrativos das universidades estaduais do Ceará foi deflagrada entre a segunda versão e a aplicação do questionário de pesquisa. Com isso, apenas um aluno compareceu para responder ao questionário de pesquisa. Os dados foram coletados e este estudo de caso se transformou em um projeto piloto para um Projeto de Iniciação Científica do PIBIC/URCA que esteve em vigor de 2014 a 2016, cujo título é A eficácia da revisão textual para o desenvolvimento da interlíngua escrita português-inglês de alunos do curso de Letras da Universidade Regional do Cariri.

${ }^{5}$ Conferir Anexo 2.
}

um texto a partir da sugestão da atividade do livro-texto utilizado em sala de aula (Cf. Figura 1). Esta atividade, por sua vez, remetia o informante à outra atividade já feita por ele na lição anterior (Cf. Figura 2).

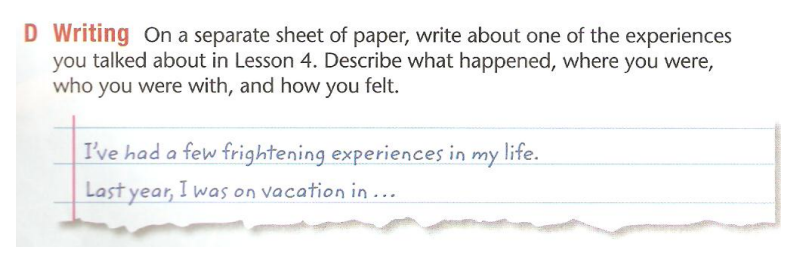

Figura 1: Top Notch, 2A, p. 12.

B On a separate sheet of paper, write lists of things you think are fascinating, thrilling, frightening, and disgusting.

Figura 2: Top Notch, 2A, p. 10.

Para diminuir a tensão e a preocupação com a linguagem, ao informante não foi dito que seu texto faria parte do piloto de um projeto de pesquisa. A primeira versão do texto foi escrita como se fosse apenas uma atividade corriqueira, como tantas outras do livro-texto. Após o recebimento da primeira versão do texto, ele foi fotocopiado, seus erros identificados e analisados.

Em um segundo momento, a primeira versão do texto foi devolvida para o informante, sem rasuras, para que ele o lesse novamente e o reescrevesse modificando as partes que ele achasse necessário. Até este segundo momento o informante não estava ciente que as versões de seu texto seriam corpus de uma pesquisa. A segunda versão do texto foi, então, recebida, fotocopiada, seus erros identificados e analisados.

Em um terceiro momento, o informante, já sabendo que seu texto faria parte de uma pesquisa, recebeu a segunda versão do texto com os erros remanescentes sublinhados para que ele mesmo indicasse se conhecia ou não as formas corretas e tentasse explicar, sempre que possível, o motivo que o levou a cometê-los. Com a finalidade de saber mais a respeito de suas crenças sobre sua aprendizagem, sobre sua concepção de erros e de correção, um questionário de sondagem foi, também, aplicado como instrumento de coleta de dados. 6

Após a conclusão da coleta de todos os dados, os erros das duas versões escritas foram classificados, analisados, contados e comparados. O referencial para a análise da interlíngua foi a variedade padrão escrita do

\footnotetext{
${ }^{6}$ Para mais informações sobre as crenças deste informante a respeito de sua aprendizagem, de sua concepção de erros e de correção, conferir Oliveira e Vieira 2016.
} 
A CONTRIBUIÇÃO DA REESCRITA PARA A APRENDIZAGEM DE INGLÊS-LE

inglês americano por ser ela usada no livro Top Notch 2 , utilizado em sala de aula. A categorização dos dados foi feita a partir da taxonomia proposta por Dulay e Burt (1974), Faerch e Kasper (1983) e reaplicadas em Figueiredo (1997) e em Vieira (2009), conforme descrição abaixo:

a) Erros Interlinguais - Dulay e Burt (1974) definem esses erros como aqueles que mostram a interferência, ou transferência negativa, de sistemas e regras da língua materna (LM) na aprendizagem de LE;

b) Erros intralinguais - São aqueles que acontecem por causa de inferências que o aprendiz faz sobre a LE que está aprendendo e não pela transferência da sua LM. Dulay e Burt (1974) nos oferecem uma subdivisão para os erros intralinguais em desenvolvimentais e únicos. Os erros desenvolvimentais representam hipóteses feitas pelo aprendiz e são similares aos erros cometidos por crianças aprendendo sua LM. Com relação aos erros únicos, estes também representam hipóteses feitas pelo aprendiz sobre a LE, porém são cometidos apenas por aprendizes adultos e não por crianças aprendendo suas LMs;

c) Erros ambíguos - São os erros que possivelmente podem ter origem na interferência da LM (interlinguais) ou em hipóteses feitas pelo aprendiz acerca de LE (desenvolvimentais).

Na próxima seção, apresentaremos os resultados e a discussão advindos da análise das duas versões do texto e do questionário de sondagem.

\section{RESULTADOS E DISCUSSÃO}

A análise do corpus foi feita partindo do contraste entre as duas versões do texto produzidas pelo informante, com as respectivas identificações dos erros, o material didático usado em sala de aula e a gramática de Quirk, Greenbaum S. nad Leech e Svartvik (1985). Algumas frases ou orações apresentam mais de um erro, mas, por questões didáticas, apenas um erro será analisado por vez. As frases ou orações que ilustram os erros para cada categoria e/ou subcategoria serão identificadas por um asterisco e o(s) termo(s) errado(s) aparecerá(ão) em itálico. Na sequência, uma proposta de reconstrução da frase mal formada será apresentada, entre parênteses será fornecida a devida tradução e, em seguida, em uma caixa de texto, os comentários do informante (ipsis litteris) sobre o erro retirado do questionário de sondagem durante o terceiro momento da coleta de dados.
O quantitativo de erros na primeira versão do texto pode ser visto na Tabela 1. Entretanto, eles não serão apresentados neste trabalho, pois como o informante teve oportunidade de reescrever seu texto, não consideramos $\operatorname{err}^{7}$ as formas idiossincráticas presentes na primeira versão, mas apenas aquelas que permaneceram na segunda versão.

\subsection{Erros Interlinguais}

\subsubsection{Não distinção lexical na LM em relação à LE}

Este tipo de erro acontece porque o aprendiz de LE não consegue perceber a diferença lexical entre termos na sua LM e na LE que está aprendendo. É bastante comum que o aluno eleja uma forma que será usada como termo superordenado para outras palavras que dividam com ela características semânticas muito próximas. Foi isso que aconteceu nos exemplos seguintes:

I. *... and we went set up our stuff there. // ... and we went to place our stuff there.// (... e nós fomos guardar nossas coisas lá.)

\begin{abstract}
Nesse primeiro caso, acredito que tenha cometido o erro devido ao fato de que em minha formação acadêmicalescolar sobre o idioma, o uso de expressões idiomáticas e gírias da língua-alvo tenham sido muito presentes. Isso fez com que, em minha construção gramatical da sentença a que o erro está acometido, colocasse o "phrasal verb" - SET UP, aqui no sentido de organizar, ao invés do termo original para tal significação, que aqui acredito que deva ser o vocábulo "ORGANIZE”, desta forma acredito, que essa simples substituição de termos, deva ser suficiente para corrigir a incoerência/inadequação gramatical a que está atrelada.
\end{abstract}

A explicação do informante deixa bastante clara a interferência da LM na escrita de LE. Em português é comum utilizarmos o verbo "organizar" com o sentido de 'guardar, cuidar, selecionar, etc'. No entanto, em língua inglesa os verbos set up e organize (mencionado pelo aluno durante sua explicação) não podem ser

\footnotetext{
${ }^{7}$ Para Corder (1974), apenas os erros sistemáticos (denominados de erros) de um indivíduo em seu processo de aprendizagem de uma nova língua devem ser analisados. Os erros assistemáticos (denominados de lapsos) não devem merecer consideração por serem de difícil interpretação e imensamente variáveis. Alinhados com esta orientação, decidimos analisar apenas os erros que permaneceram após a reescrita do texto.
} 
A CONTRIBUIÇÃO DA REESCRITA PARA A APRENDIZAGEM DE INGLÊS-LE

Tabela 1: Quantitativo de Erros da $1^{\mathrm{a}}$. Versão do Texto.

\begin{tabular}{|c|c|c|c|c|}
\hline \multicolumn{3}{|c|}{ CATEGORIAS DE ERROS } & NÚMEROS ABSOLUTOS & NÚMEROS PERCENTUAIS \\
\hline \multicolumn{3}{|c|}{ Erros Interlinguais } & 7 & $33,33 \%$ \\
\hline \multirow{2}{*}{$\begin{array}{l}\text { Erros } \\
\text { Intralinguais }\end{array}$} & Desenvolvimentais & 8 & \multirow{2}{*}{11} & \multirow{2}{*}{$52,38 \%$} \\
\hline & Únicos & 3 & & \\
\hline \multicolumn{3}{|c|}{ Erros Ambíguos } & 3 & $14,29 \%$ \\
\hline \multicolumn{3}{|l|}{ Total } & 21 & $100 \%$ \\
\hline
\end{tabular}

empregados no sentido de "guardar", como foi o termo requisitado pelo contexto.

II. *... and at night, we went to the mall.//... and in the evening we went to the mall.// (...e à noite nós fomos ao shopping.)

\begin{abstract}
Aqui acredito que a incoerência tenha sido com relação ao uso do termo já identificado em relação ao período do dia a que estava me referindo na situação do texto, haja visto que "AT NIGHT" refere-se à um período mais avançado da noite em língua inglesa, então teríamos que nos utilizar do termo "IN THE EVENING” de forma que o termo ficasse semanticamente coerente com relação ao contexto situacional daquilo que eu estava querendo dizer.
\end{abstract}

Pela explicação fornecida, constatamos que o informante conhece a forma correta que deveria ter sido empregada neste contexto. O curioso neste exemplo é que na primeira versão do texto ele havia escrito a forma correta (in the evening), mas durante a reescrita empregou a forma at night.

III. *I was at the top of the biggest building of the whole city...// I was at the top of the tallest building of the whole city.// (Eu estive no topo do prédio mais alto da cidade.)

A única solução que me ocorre é o de substituir o adjetivo no superlativo "BIG" por "TALL" também no superlativo devido ao fato deste estar se referindo a uma construção humana de uma altura considerável.

Apesar de ter apontado o substituto correto, pela explicação não ficou claro se o informante está seguro que o adjetivo tall é realmente o vocábulo que deve ser empregado como substituto para big. O fato de ser "uma construção humana de uma altura considerável" não permite que tiremos conclusões definitivas a respeito da assertiva do aluno.
IV. * ... the sea image was breathless.// ... the view of the sea was breathtaking.//(.. a imagem do oceano era de tirar o fôlego.)
Mais uma vez um conflito entre a LE e a LM me deixaram confusos nessa hora. Portanto a construção do termo ficou em desacordo com a norma padrão da LE em questão. Pode- ria ter substituído por "VIEW OF THE SEA". Foi a primeira coisa que me veio à cabeça.

Este caso é semelhante ao anterior em que ele utiliza o termo imagem (imagem), no lugar de view (vista). Podemos concluir com este exemplo e o anterior, corroborados pelo depoimento, que o termo superordenado é o que primeiro vem à mente do informante quando ele tenta produzir um texto (neste caso escrito) em sua interlíngua.

V. * I truly hope that some day I may come back there. // I truly hope that someday I may come back there. // (Eu sinceramente espero que algum dia eu possa voltar lá.)
Acredito que nesse termo em específico, a inadequação gramatical tenha ocorrido pela simples separação dos termos "SOME" $e$ "DAY”, já que nesse sentido o vocábulo é único e individual, sendo escrito como "SO- MEDAY".

Apoiado na sequência dos termos que formam este advérbio na língua portuguesa, o qual é construído com os vocábulos 'algum' e 'dia', o informante apenas juntou os vocábulos referentes na língua inglesa e os empregou em seu texto. Entretanto seu uso está em desacordo com a língua inglesa, pois o termo some day faz referência a um dia específico no futuro, ao passo que someday faz referência a um dia distante e indeterminado no futuro. 
A CONTRIBUIÇÃO DA REESCRITA PARA A APRENDIZAGEM DE INGLÊS-LE

\subsubsection{Não distinção gramatical na LM em relação à LE}

Esse tipo de erro ocorre porque o aprendiz não percebe que uma determinada distinção gramatical existe na LE, mas não na sua LM.

I. * We've been to a lot of places. // We went to a lot of places.//(Nós fomos para muitos lugares.)

Me ocorreu que na época da escrita do texto estávamos estudando justamente o "Present Perfect”, o que pode ter sido uma das razões pelas quais me utilizei dessa forma na escrita.

Para este caso, o informante não forneceu uma explicação plausível para o erro, nem apresentou a forma correta do tempo verbal. Ele apenas justificou a presença do presente perfect pelo fato de estar estudando, quando da produção de texto, este tempo verbal.

$\mathrm{Na}$ língua inglesa, as ações iniciadas e finalizadas no passado com tempo definido são expressas pelo Simple Past (passado simples), e as ações iniciadas no passado com tempo indefinido e que ainda são refletidas no presente são expressas pelo Present Perfect (Presente Perfeito). Essa distinção gramatical, às vezes, é difícil de entender entre o inglês e o português. Por isso os aprendizes cometem erros, como este apresentado, utilizando o passado simples em vez do pretérito perfeito.

\subsection{Erros Intralinguais Únicos ${ }^{8}$}

Um dos tipos de erros únicos é aquele causado pela adição desnecessária do marcador de infinitivo to ao verbo modal. Nas locuções verbais em língua inglesa, o segundo verbo geralmente se posiciona após o marcador de infinitivo to. Entretanto, alguns verbos, como os auxiliares modais, fogem a esta regra e não são acompanhados por este marcador específico como no exemplo que segue:

I. * We went to the mall so we could do some shopping, watch movies to enjoy the food at the great restaurants there.// We went to the mall so we could do some shopping, watch movies and enjoy the food at the great restaurants there.//(Nós fomos ao shopping, assim pudemos fazer algumas compras, assistir a filmes e saborear a comida dos bons restaurantes de lá.)

Acredito que aqui o meu erro foi o de ter usado o verbo no infinitivo inadequadamente.

\footnotetext{
${ }^{8}$ Durante a análise do corpus da segunda versão do texto não foram encontrados erros intralinguais do tipo desenvolvimentais.
}

Para este erro, o informante não reescreveu a forma correta, mas conseguiu apontar que o erro estaria na presença do marcador de infinitivo to.

\subsection{Erros Ambíguos}

\subsubsection{Omissão do marcador de infinitivo to}

Em inglês, assim como em português, é comum a formação de locuções verbais nas quais o verbo principal é apresentado na sua forma infinitiva. A ausência do marcador de infinitivo to pode ter origem na língua portuguesa (interlingual), já que nesta língua não há a necessidade de um marcador específico, ou em hipóteses que o aluno faz sobre a língua inglesa (intralingual), em especial com as locuções construídas com verbos modais em que o marcador não é exigido.

I. *... we went $\oslash$ set up our stuff there.//... we went to place out stuff there.// (... nós fomos guardar nossas coisas lá.)

Para a ausência do marcador de infinitivo, o informante não forneceu nenhuma explicação, o que nos leva a crer que sua ausência não foi percebida.

\subsubsection{Os erros ocasionados por generalização acontecem quando o aprendiz conhece uma determinada regra e a aplica em qualquer contexto}

Vejamos o exemplo abaixo:

I. *... the sea image was breathless.//... the view of the sea was breathtaking.// (... a vista do oceano foi de tirar o fôlego.)

\begin{abstract}
Aqui tenho quase certeza de que ao querer dizer para o leitor, a ideia de que "A VISTA DO MAR FOI DE ME DEIXAR SEM FÔLEGO”, ou seja, que a vista era extremamente bela, que o termo utilizado foi erroneamente colocado como "BREATHLESS", que realmente/literalmente quer dizer que a pessoa está sem fôlego, diferentemente da ideia semântica que eu queria dizer. Portanto para substituir tal termo, acredito que o melhor termo que dê conta dessa significação, em específico seja o vocábulo "BREATHTAKING”.
\end{abstract}

Neste caso, há duas explicações plausíveis para o emprego da palavra breathless. A primeira é a de que o informante pode ter se apoiado na estrutura morfológica da língua portuguesa (interlingual) ao juntar as palavras 
breath (fôlego) e less (sem), o que de fato forma a expressão "sem fôlego". No entanto, esta expressão equivale em português a "falta de ar", o que não é o sentido desejado para a sentença. A segunda explicação é que ele conhece que o sufixo -less em inglês significa "sem" e pode ser aplicado a substantivos formando palavras como cloudless (sem nuvens), powerless (sem poder) e generalizou seu uso aplicando-o, também, ao substantivo breath (intralingual).

Durante a análise, encontramos no segundo parágrafo a seguinte construção:

II. * We spent hole mornings at the beach.// We spent whole mornings at the beach.//(Nós passamos manhã inteiras na praia.).

Esse tipo de construção se caracterizaria como erro desenvolvimental ocasionado pela não relação entre grafemas e fonemas da LE. No entanto, ao continuar a análise do texto encontramos no terceiro parágrafo a construção I was at the top of the biggest building of the whole city... na qual a palavra whole aparece em sua forma correta. Ao ser indagado sobre a construção do segundo parágrafo, o informante não conseguiu perceber o erro:

Não consegui compreender o contexto do erro. A única forma substituta plausivel que me veio à mente foi "SPEND HOLE", mas não tenho certeza se é realmente esse o erro que cometi.

No entanto, decidimos desconsiderar a forma hole como erro e considerá-la como lapso, já que o informante conseguiu escrever a palavra em sua forma correta, exigida pelo contexto semântico, no parágrafo seguinte.

A Tabela 2 mostra o quantitativo de erros da segunda versão do texto escrito.

Ao comparar a primeira e a segunda versão do texto, percebemos que houve uma diminuição de 57,15\% (12 erros) de erros na reescrita do texto. Os erros mais autocorrigidos foram os desenvolvimentais e os que mais permaneceram na segunda versão foram os interlinguais. Dos nove erros que permaneceram após a reescrita do texto, o informantesó não conseguiu corrigir dois deles.

\section{CONCLUSÃO}

A análise das versões escritas do texto apontou uma redução bastante significativa de erros entre a primeira e a segunda versão $(57,15 \%)$, o que por si só já valida a prática da reescrita em sala de aula de LE. Apesar de nove erros permanecerem na segunda versão do texto, $\mathrm{o}$ informante conseguiu indicar e explicar a forma correta de sete erros quando a segunda versão do texto lhe foi entregue com os erros sublinhados. Para este estudo, os números sugerem que os erros aconteceram por pressão de tempo, pelo estresse de atividades como estas ou por falta de atenção do aluno. Esses fatores são usados pela teoria da interlíngua para explicar o surgimento de erros que já deveriam ter sido superados no estágio atual de aprendizagem em que o aprendiz se encontra. Esse fenômeno, chamado de backsliding, interfere enormemente tanto na produção oral como na produção escrita de alunos.

Percebemos que a influência da LM ainda é intensa no estágio em que o informante se encontra, especialmente pela não distinção de vocábulos da LM em relação à LE. Algumas explicações dadas por ele acerca dos erros remanescentes não nos permitiram concluir se ele realmente conhecia a forma correta ou se apenas aplicou outra forma alternativa quando solicitado a explicar os motivos que o levaram a cometer os erros. Consideramos que este fato é comum durante o processo de aprendizagem de uma LE, quando os contextos de uso nem sempre acompanham a rapidez da aprendizagem dos vocábulos.

Estabelecer a prática de reescrita como uma atividade constante na produção de textos em LE e dar aos alunos a oportunidade de discutir os fatores que interferem na sua aprendizagem fazem com que os alunos se tornem mais conscientes dos processos operantes no decorrer de sua aprendizagem, principalmente pelo fato do aprendiz de LE estar lidando com uma interlíngua que está em constante mudança. Essas atividades podem contribuir consideravelmente para a otimização dos conhecimentos e consequente desenvolvimento da LE.

\section{REFERÊNCIAS}

CORDER, S. P. Error analysis: perspectives on second language acquisition. In: RICHARDS, J. C. (Ed.). The Significance of Learners Errors. London: Longman, 1974. p. 19-27.

D'ANDREA, C. F. B.; RIBEIRO, A. E. Retextualizar e reescrever, editar e revisar: Reflexões sobre a produção de textos e as redes de produção editorial. Veredas-Revista de Estudos Linguisticos, Federal University of Juiz de Fora (UFJF), v. 1, n. 1, p. 64-75, 2010.

DULAY, H. C.; BURT, M. K. Error analysis: perspectives on second language acquisition. In: 


\begin{tabular}{|c|c|c|c|c|}
\hline \multicolumn{3}{|c|}{ CATEGORIAS DE ERROS } & NÚMEROS ABSOLUTOS & NÚMEROS PERCENTUAIS \\
\hline \multicolumn{3}{|c|}{ Erros Interlinguais } & 6 & $66,70 \%$ \\
\hline \multirow{2}{*}{$\begin{array}{l}\text { Erros } \\
\text { Intralinguais }\end{array}$} & Desenvolvimentais & - & \multirow{2}{*}{1} & \multirow{2}{*}{$11,20 \%$} \\
\hline & Únicos & 1 & & \\
\hline \multicolumn{3}{|c|}{ Erros Ambíguos } & 2 & $22,10 \%$ \\
\hline \multicolumn{3}{|l|}{ Total } & 9 & $100 \%$ \\
\hline
\end{tabular}

RICHARDS, J. C. (Ed.). You Cant Learn without Goofing. London: Longman, 1974. p. 55-27123.

FAERCH, C.; KASPER, G. Strategies in interlanguage communication. In: FAERCH, C.; KASPER, G. (Ed.). Plans and strategies in foreign language communication. London: Longman, 1983. p. 20-60.

FIAD, R. S.; BARROS, J. d. S. O papel da intercalação na reescrita. Revista Brasileira de Linguística Aplicada, SciELO Brasil, v. 3, n. 1, p. 9-23, 2003.

FIGUEIREDO, F. J. Q. Aprendendo com os Erros: uma perspectiva comunicativa de ensino de línguas. 2. ed. Goiânia: UFG, 1997.

FLOWER, L.; HAYES, J. R. A cognitive process theory of writing. College composition and communication, JSTOR, v. 32, n. 4, p. 365-387, 1981.

LUNA, R. M. Interlanguage in undergraduates' academic english: Preliminary results from written script analysis. Revista de investigación e innovación en la clase de idiomas, Servicio de Publicaciones de la Universidad de Alcalá, v. 19, n. 1, p. 60-73, 2010.

MENEGASSI, R. J. Da revisão a reescrita: operações lingüísticas sugeridas e atendidas na construção do texto. Mimesis, Bauru, v. 22, n. 1, p. 49-68, 2001.

MENEGOLO, E. D. d. C. W.; MENEGOLO, L. W. O significado da reescrita de textos na escola: a (re) construção do sujeito-autor. Ciências \& Cognição, v. 4, n. 1, p. 73-79, 2011.

OLIVEIRA, M. H.; VIEIRA, C. R. Crenças de alunos do curso de letras sobre o erro e a correção do erro na escrita em língua inglesa. Miguilim-Revista Eletrônica do Netlli, v. 5, n. 2, p. 30-46, 2016.

QUIRK, R.; GREENBAUM S. NAD LEECH, G.; SVARTVIK, J. A Comprehensive Grammar of the English Language. 1. ed. London: Longman, 1985.
SELINKER, L. Error analysis: perspectives on second language acquisition. In: RICHARDS, J. C. (Ed.). Interlanguage. London: Longman, 1974. p. 31-54.

SEOW, A. Methodology in language teaching: and anthology of current practice. In: RICHARDS, J. C.; WILLY, A. R. (Ed.). The writing process and process writing. Cambridge: Cambridge University, 2002. p. 315-320.

VIEIRA, C. R. O erro na aprendizagem de inglês-LE: uma análise da interlíngua de aprendizes brasileiros. Dissertação (Mestrado em Linguística Aplicada) - Universidade Estadual do Ceará, Fortaleza, 2009.

WANG, Y. Differences in 11 and 12 academic writing. Theory \& Practice in Language Studies, Citeseer, v. 2, n. 3, p. 637-641, 2012.

WOLFERSBERGER, M. L1 to 12 writing process and strategy transfer: A look at lower proficiency writers. Teaching English as a Second or Foreign Language, http://writing. berkeley. edu/TESL-EJ/, v. 7, n. 2, p. $1-12,2003$. 